\title{
Incorporating Novel Ecosystems and Layered Landscapes for Ecological Restoration in Cities
}

\author{
Valentin Schaefer \\ School of Environmental Studies, University of Victoria, Victoria, Canada
}

Email address:

schaefer@uvic.ca

\section{To cite this article:}

Valentin Schaefer. Incorporating Novel Ecosystems and Layered Landscapes for Ecological Restoration in Cities. American Journal of Life Sciences. Vol. 5, No. 6, 2017, pp. 164-169. doi: 10.11648/j.ajls.20170506.13

Received: December 1, 2017; Accepted: December 10, 2017; Published: January 2, 2018

\begin{abstract}
Ecological restoration in cities is problematic. The natural environment is radically altered with large areas of impervious surfaces, invasive species and a parallel artificial infrastructure for transporting water, waste and energy. There are also competing goals to meet the needs of people as identified in Official Community Plans. Cities are novel ecosystems and the restoration targets often do not align well with the natural ecosystems that historically existed in the area. The objective of this study is to use the University of Victoria campus as an example of urban restoration that incorporates novel ecosystems and takes a layered landscapes approach to address the complex socio-ecological histories of a site. Hobbs Creek and its ravine, Mystic Vale, are a particular focus. Instead of trying to restore the original fish-bearing stream and forest, the University of Victoria has used a novel ecosystem approach to set a suitable restoration target for an ecosystem that is capable of maturing, has a stable trajectory and is resilient. The university has an ongoing program of invasive species removal, reducing stream bank erosion and managing human impacts that is consistent with applying the layered landscapes concept, addressing the diverse values and visions of people as well as ecological integrity. In cities, the novel ecosystem approach acknowledges that complex socio-ecological histories of a site have shaped them over time and play a major role in determining a site's future. Combining the layered landscapes perspective with the novel ecosystems concept as was done in this project is an effective approach to ecological restoration in cities.
\end{abstract}

Keywords: Layered Landscapes, Novel Ecosystems, Ecological Restoration, Ecological Memory, Culturally Modified Landscapes, Restoration Target

\section{Introduction}

The presence of introduced invasive species and the loss of ecological memory in cities may lead to the formation of emergent or novel ecosystems [1]. Unique species assemblages of invasive and native species may be the new reality in some cases [2]. Constituent ecosystems within the city can be viewed as complex adaptive systems that combined may make up novel ecosystems [3].

Ecological restoration in cities differs greatly from restoring natural areas. A city is a place created by and for people and any restoration of natural areas in the city must incorporate the needs and wants of people. The competing interests of people and nature, and among people themselves, results in a situation where there are layers of activity and layers of interests that need to be addressed. The World Health Organization has recently brought greater attention to the importance of urban biodiversity to the well-being of people [4]. A simple indicator of biodiversity in a city is to measure impervious surface and an effective way of improving biodiversity is to restore more of the natural landscape which requires addressing more than just the science of ecosystems [5]. Although dealing with nature in the city is primarily the realm of the natural sciences, dealing with people in the city is primarily the realm of the social sciences, and the interaction between the two forms the urban ecosystem.

Urbanization destroys and fragments habitat to make space for buildings and roads and continues disturbing the landscape to maintain the built environment. In the process, the remaining natural environment has lost its ecological memory, one of the major components of ecosystem resilience [6]. The loss of ecological memory at a site may make it more susceptible to colonization by invasives and 
make it more difficult to restore to its natural state $[7,8]$. This is most acute in urban situations where the original soil has been removed and replaced with a base of sand and gravel covered with sterilized topsoil imported from somewhere else.

The presence of invasive species and the loss of ecological memory may lead to the formation of emergent or novel ecosystems [9]. Over the last several decades, natural ecosystems in urban areas have been developing into such novel ecosystems. Persistent unique species assemblages of invasive and native species maybe the new reality in some cases [10].

Constituent ecosystems within the city can be viewed as complex adaptive systems [11]. The essential elements of complex adaptive systems that need to be considered in an urban context include sustained diversity and individuality of components, localized interactions among those components and an autonomous process that selects a subset from among those components for replication and enhancement. Novel ecosystems can be composed of such complex adaptive systems that include invasive species, as noted earlier. There may not be any overarching processes that operate on the whole system.

Changes to these adaptive systems come from chance events at local levels that reinforce emergent properties. Complex adaptive systems for heavily managed systems like agriculture, forestry, and presumably cities, have their simplified systems imposed from without (exogenously) rather than from within. The events in imposing these systems can be due to environmental variation but in cities they are also created by people. Aggregations of species will develop flows of nutrients and energy and the ecosystem will undergo a process of self-organization and take shape. As a result, these ecosystems are fragile, so a single stressor such as an invasive species outbreak can cause system crashes in the absence of adaptive responses.

Species in cities tend to fall into three broad response categories - urban adaptors, urban avoiders and urban exploiters [12]. Urban adaptors include species commonly found in more natural environments that have been selected to exploit additional resources, such as ornamental vegetation found in moderately developed areas. These species have adapted to urbanized sites, have been successful in locating new shelter and food resources and have avoided predation and disease. However, they still prefer natural, undisturbed habitats. Examples of urban adaptors include Dark-eyed Junco (Junco hyemalis), Northern Harrier (Circus cyaneus), Pileated Woodpecker (Dryocopus pileatus), big brown bat (Eptesicus fuscus) and Black-capped Chickadee (Poecile atricapillus).

Urban avoiders lose habitat because they are very sensitive to changes in the landscape, so they typically avoid cities [13]. They include species that need interior habitats or ecotypes not typical of a city. Examples include the Warbling Vireo (Vireo gilvus), tailed frog (Ascaphus truei), Douglas squirrel (Tamiasciurus douglasii) and Hairy Woodpecker (Picoides villosus).
Urban exploiters benefit from the disturbed habitat caused by urban development. Their densities are higher in urban environments as they exploit new food sources and thrive in the absence of their natural predators. Urban exploiters are commonly introduced species that are generalists, such as European Starling (Sturnus vulgaris), eastern gray squirrel (Sciurus carolinenesis), crows (Corvus spp.), House Sparrow (Passer domesticus) and gulls (Larus spp.).

As more natural habitat is destroyed in cities, there is increased fragmentation and existing fragments are reduced in size. This trend favors an increase in urban adaptor species and a decrease in urban avoiders. It also results in an increase in the population sizes of urban exploiters with the consequent decrease in their usual natural prey populations, resulting in prey suppression of these natural prey species. Range shifts north over the past several decades for some urban species such as the House Finch (Carpodacus mexicanus) and Northern Cardinal (Cardinalis cardinalis), perhaps due to climate change [14], have introduced new species into some cities.

Certain feeding guilds are favored by urbanization. The minimum area that can support a community of insect-eating birds is 40 ha compared to just 2 ha for seed-eating birds ([15], [16], [17], [18]). The smaller patch sizes in cities offer better habitat for seed-eating birds such as finches, sparrows and thrushes with a decrease in insect feeding species, especially aerial feeders. Similarly, smaller patches are less likely to have the interior habitat necessary for some species such as Red-eyed Vireo (Vireo olivaceus).

Novel Ecosystems: All of these factors combined make it unlikely that a disturbed area can feasibly be returned to its historical natural state. The restoration target instead focuses on creating an ecosystem that maximizes natural functions while accommodating invasive species and the built environment. An ecosystem that differs in composition and/or function from present and past systems is called a novel ecosystem, which arises primarily through human action, climate change and invasive species. Novel ecosystems are constantly emerging and have no natural analogues.

In ecological restoration, we may still attempt to return a disturbed area to its historical natural state if the biotic and abiotic factors have not been degraded beyond the point from which the ecosystem can recover. The restoration of such areas addresses deficiencies. One consideration is determining what we mean by historical. In the case of North America this usually means before European contact, although the case can be made that before European contact indigenous peoples had already greatly changed the landscape so what European explorers saw when they arrived was not a pristine wilderness but rather a culturally modified landscape [19].

However, returning an ecosystem to its historic natural state may not be possible if both the abiotic and biotic factors have significantly deviated. With novel ecosystems, it is not a matter of thinking "outside the box" as may happen in being innovative when returning a disturbed area to its historical 
natural state, the "original box." Instead, what we are looking at is establishing a "new box" [20]. With the novel ecosystem concept, we entertain new species assemblages. We focus more on key species of conservation interest, ecosystem function and resilience rather than fidelity to an historical assemblage of native species. Invasive species may be controlled with no realistic option of eliminating them. An example is the conservation of the monarch butterfly (Danaus plexippus) in the Monarch Butterfly Grove at Pismo Beach, California, where the invasive blue gum (Eucalyptus globulus) is used to restore roosting habitat (Figure 1).

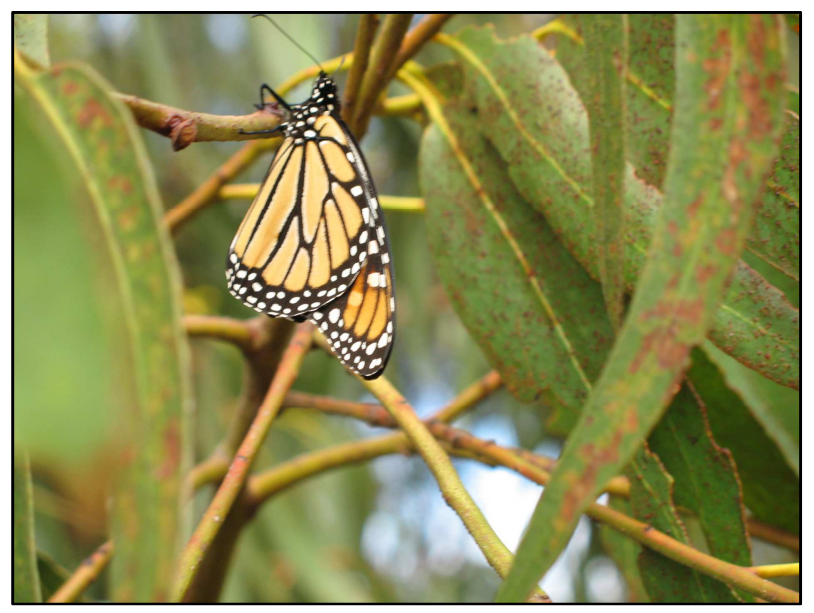

Figure 1. A Monarch Butterfly roosting on eucalyptus in Pismo Beach. Photo: Schaefer.

Layered landscapes: Urban ecology needs to consider more than environmental factors, there are social and political influences as well. Context for the site design is critical for a project to endure. To really work, a design requires that we understand the site's past history, current influences - both on and off site, and future impacts. This process of understanding a site is sometimes called "listening" and encompasses ecological, social, and political factors [21]. Each factor can be seen as a layer. The factors include the complex socio-ecological histories that have shaped a place over time. Prior uses, meanings, and ecologies also shape possibilities for the future and determine the potential for ecological restoration.

\section{Materials and Methods}

The layered landscapes approach acknowledges the complexity of a site and integrates ecological values with social and cultural values to create a more authentic approach to landscape architecture. Restoration goals often clearly intertwine with social, political, and economic considerations and restoration planning at these sites engages diverse values and visions. Such community-engaged restoration planning is challenging, as it can bring forward competing visions for a site and stark disagreements about its future.

The University of Victoria campus in Victoria, BC, Canada, is a good example of a layered landscape. A case study of the layered landscapes concept itself [22] dealt with the transformation of a former US Army Jefferson Proving Ground munitions testing area into the Big Oaks National Wildlife Refuge in Indiana. The University of Victoria campus also has a military connection, as the campus was established on 56 ha of land owned by the Canadian Federal Government and the Hudson's Bay Company in 1963. It was a military training base during World War II and had 40 useful barracks on the site.

Unlike the Jefferson Proving Ground example, however, there was no issue with heavy metals in the soil from munitions. On the contrary, prior to European settlement the University of Victoria property was used by local First Nations to grow an important staple food, camas (Camassia spp.), and is a good example of a culturally modified landscape. The whole of southern Vancouver Island is in the biogeoclimatic zone CDFmm - Moist Maritime Coastal Douglas-fir. The region is instead a Garry Oak Ecosystem because First Nations had been burning the area from time immemorial to prevent the natural succession to a Douglasfir forest, thus maintaining a community of Garry Oaks (Quercus garryana), with the associated meadow community. Recognition of the role of First Nations management practices in maintaining Garry Oak Ecosystems is a key consideration in how this ecosystem is restored today and is incorporated as one of the layers [23]. There are still camas meadows on campus as well as evidence of burial cairns from previous First Nations communities.

On the other hand, like the Jefferson Paving Ground example that had a species of interest on the property, the Burrowing Owl (Athene cunicularia), there was a breeding colony of Eurasian Skylark (Alauda arvensis) on the university campus. Although an introduced species, it was well-loved and the subject of student protests when the habitat of the species was destroyed to construct the David Strong Building. Similarly, a subject of debate today is that some habitat in the Cunningham Woods may soon be lost due to personal safety concerns for people walking across the campus at night as identified in the 2015 update of the University's Campus Plan [24].

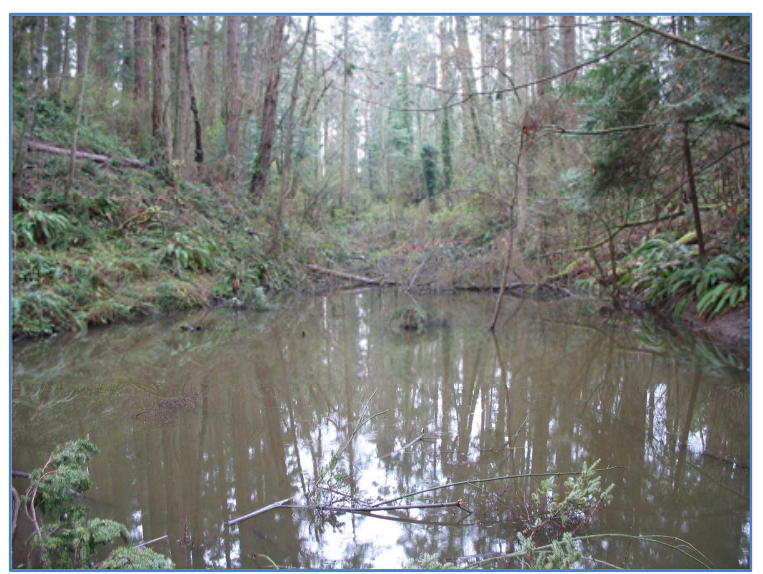

Figure 2. Canoe Pond in Mystic Vale on the University of Victoria campus has no waterway that can be used by a canoe going into or out of the pond. Photo: Schaefer. 
The military connection in the University's past is still evident in the name "Canoe Pond", a small isolated wetland in Mystic Vale that is a large ravine on campus (Figure 2). Since you cannot canoe to or from the pond on Hobbs Creek the name is a puzzle to many people, but the name makes sense because the army used it to teach canoeing.

Mystic Vale and Hobbs Creek today are examples of layered landscapes and competing uses. An Invasive Species Management Strategy was developed for these sites in 2016 [25]. Hobbs Creek receives the drainage from a large storm drain in Oak Bay that subjects the creek to the typical floods and droughts common in urban creeks with large areas of impervious surface in their watersheds. The erosion of the banks and the siltation of the creek are so serious that the university developed a Hobbs Creek -Mystic Vale 5-year restoration plan, last updated in 2009. Additional layers present in Mystic Vale come from dog walkers as off-leash dogs that run up and down the slopes of the ravine into and out of the creek contribute to erosion problems, and from local daycares and elementary schools that bring children into the ravine who are then allowed to run around freely, destroying vegetation and disturbing wildlife. One small solution to the siltation problem in Hobbs Creek was to install page wire fencing around Canoe Pond.

However, the erosion issues the plan identifies for Hobbs Creek can only be addressed with limited success in the instream environment. Restoration efforts such as wattles to stabilize the banks and weirs in the creek to trap sediment are overwhelmed by floodwaters from the impervious surface area in the watershed. These are often destroyed by heavy water flows contributing to the siltation problem. The only long-term solution is to install more permeable surfaces and to take a watershed approach. The University has created rain gardens in the watershed on campus to improve infiltration and to help with the problem of stream flow but the solution requires a much broader watershed scale approach that needs to include broader urban planning measures within the City of Oak Bay.

\section{Results and Discussion}

A major approach to restoring Hobbs Creek and Mystic Vale was to develop an Invasive Species Management Strategy, recognizing that this was a layered landscape. There was considerable consultation to identify competing values and visions and to try to develop solutions. These consultations occurred with university students, faculty and staff, three student associations, the Office of Indigenous Affairs, Facilities Management, Campus Planning and external community groups. The results were presented at an Open House for final input and a comprehensive final report was produced, along with an accompanying Volunteer Orientation Manual. Many students had been involved with invasive species removal and planting of native vegetation to restore Hobbs Creek and Mystic Vale as experiential learning exercises through various classes and as capstone projects through the Restoration of Natural Systems (RNS) Program at the University. The author of this article is the Academic Administrator of the RNS Program and oversees the studentbased Ecological Restoration Volunteer Network (ERVN) on campus.

Typically, in a one year period the ERVN would directly engage students who would put in hundreds of volunteer hours to remove invasive species, plant native vegetation and install wattles to stabilize the banks of Hobbs Creek. The ERVN also regularly works with two courses in particular each semester: ES341 Past, Present and Future Ecologies, and ES321 Ethnoecology, which would dedicate one class each semester to remove English ivy (Hedera helix) and other invasive species (Figure 3). In taking an Early Detection Rapid Response (EDRR) approach, a priority is to remove English ivy from the trunks of trees to prevent berries of this species from being eaten by birds and dispersed. The Sustainability Office and the Department of Facilities Management provided funds and were also involved in planning to ensure that the restoration activities were consistent with the larger planning documents for the campus.

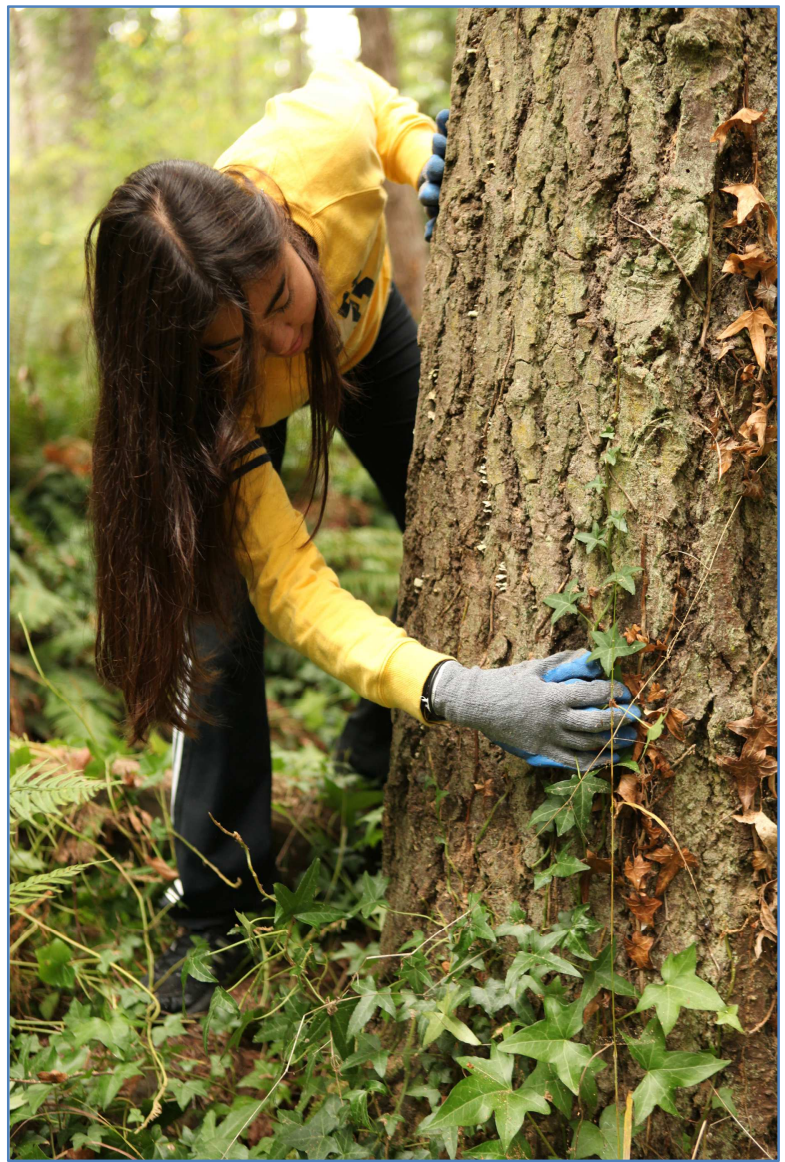

Figure 3. A student in an Ethnoecology class removes English ivy from the trunk of a Douglas-fir (Pseudotsuga menziesii) in Mystic Vale. The vertical vines of English ivy produce berries that when eaten by birds can be widely dispersed. Photo: Ecological Restoration Volunteer Network.

Mystic Vale is part of Greater Victoria's urban forest. The urban forest is recognized as a major asset in sustainable land 
use planning that includes models for stormwater management, watershed scale local planning, stream restoration and greenways networks. Despite the importance of the urban forest it is rapidly being degraded and is poorly protected. Tree protection bylaws and other forms of protection are inadequate and tree management practices are out of date. A study on urban forest canopy cover in Victoria, BC from 1986-2005 [26], found that tree cover decreased by $8.3 \%$ and impervious surface increased by $13.2 \%$. The denser tree cover class of more than $75 \%$ of the land covered decreased by $16.1 \%$, showing that intact forest was lost to development. In the same study the amount of impervious surface that covered $75 \%$ or more of the cells increased by $19.8 \%$ while the cells with less than $5 \%$ impervious surface decreased by $9.2 \%$.

The cost of purchasing land today in major cities is prohibitive, so it is often not the primary option for restoring and conserving biodiversity. Stewardship is a reasonable alternative. A number of publications have offered good options for conserving biodiversity beyond establishing protected areas. These begin with community design that incorporates principles of Smart Growth to build more compact communities, Low Impact Development to regulate the water cycle and incentives such as density bonusing, and take a broad approach that encompasses subsidies, tax incentives and conservation covenants [27].

The impact of nature in the city on the physical and emotional well-being of its residents and the healthy development of its children is increasingly recognized. Many residents participate in restoration projects because of their impacts in building community and creating healthy living spaces. They may not be concerned about contributing to biodiversity but rather about the broader goal of ecological health that offers benefits in clean drinking water, clean air and the availability of greenspace.

Removal of invasive species and site clean-ups are popular activities that increase biodiversity because they show immediate results. They serve as gateway activities for more involved actions to restore a site. Other stewardship activities include providing artificial structures such as bee blocks, bird boxes, bat boxes, butterfly boxes and woody debris for amphibians. Continued interest can lead to community engagement in planning processes and political action.

Community engagement is an important aspect of an urban restoration project. In Greater Vancouver, BC, for example, a primary motivation of the Green Links restoration projects was to involve schools to help build community [9]. This is an example of focal restoration [28]. Many of the Green Links projects could have been done in a day by the organizers themselves (Figure 4). Instead, they spent days over a period of 2-3 weeks talking with teachers, giving presentations in classes and doing workshops in the schools before going to the planting site with the ultimate purpose of restoring habitat, just to engage community.
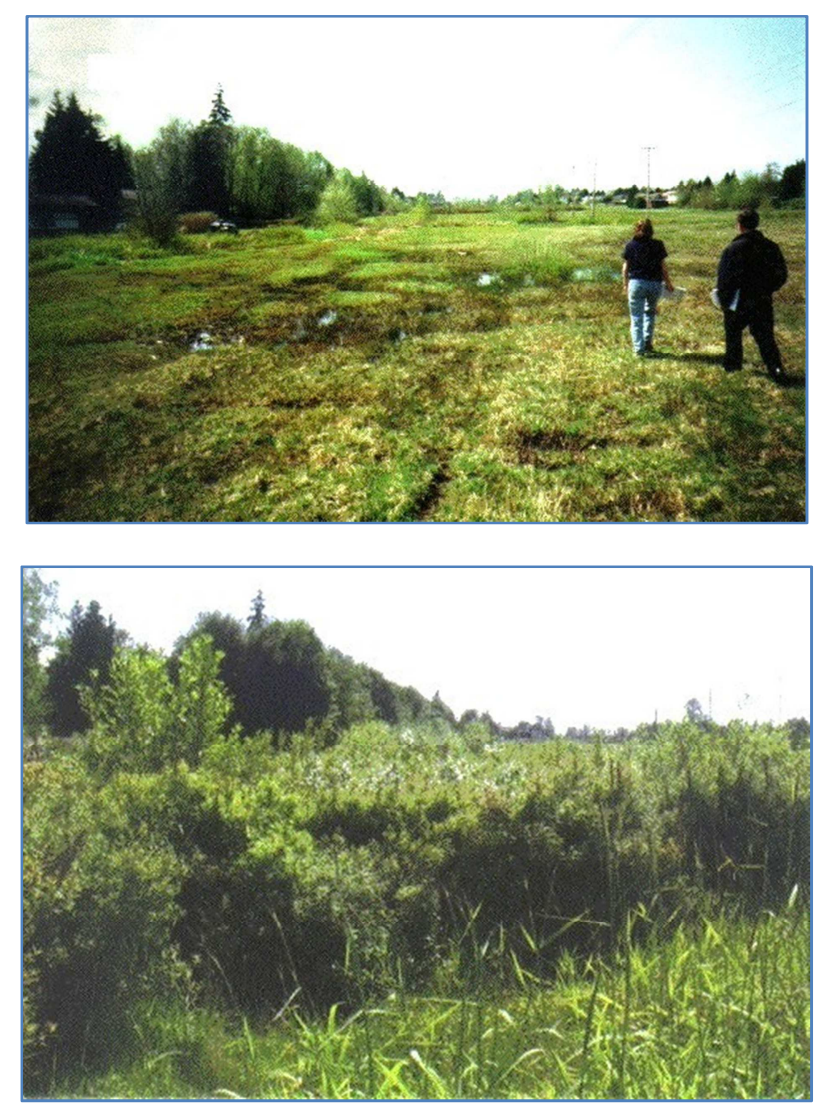

Figure 4. A before (upper) and after (lower) picture of a Green Links project in a hydro utility right-of-way. The site was the focus of elementary school plantings on Earth Days over four years which resulted in the conversion of a grassy corridor with little wildlife value into one of dense shrub growth the supports healthy songbird populations. Only shrubs were used because of height restrictions for trees growing under high voltage transmission lines. Photo: Institute of Urban Ecology.

Related to quality of life is the issue of public safety, another layer in urban ecological restoration. The safety of people is one driver in the location and selection of plants for projects the public will use. Such projects followed the principles of Crime Prevention Through Environmental Design (CPTED), another layer on the landscape [29].

\section{Conclusion}

Many cities are situated in biologically rich sites. Maintaining ecological health in cities is integral to the health of the greater ecosystems in which they occur. Understanding that cities are in fact novel ecosystems and layered landscapes offers a more realistic assessment of their ecology and enables us to more effectively restore and manage their natural potential. The synthesis of the novel ecosystem and layered landscapes concepts is a new development in the field of ecological restoration in cities and has important potential consequences in maximizing the biological potential of natural areas in cities and managing nature in the city to improve the quality of life and health of its residents. There is a great need for more research in this important area in the future. 


\section{Acknowledgements}

The author is grateful to Anny Schaefer for her editorial comments. The author presented this paper at the Canadian Society for Ecology and Evolution conference in Victoria, BC, May 8, 2017, in a symposium on Accelerating Urban Ecology in Canada: Identifying current research approaches, gaps and needs in Canadian cities, organized by Carly Ziter of the University of Wisconsin-Madison and Matthew Mitchell of the University of British Columbia.

\section{References}

[1] Hobbs, R. J., A. Salvatore, J. Aronson, J. S. Baron, P. Bridgewater, V. A. Cramer, P. R. Epstein, J. J. Ewel, C. A. Klink, A. E. Lugo, D. Norton, D. Ojima, D. M. Richardson, E. W. Sanderson, F. Valladares, M. Vilà, R. Zamora, and M. Zobel. (2006). Novel ecosystems: theoretical and management aspects of the new ecological world order. Global Ecology and Biogeography 15:1-7.

[2] Hobbs, R. J., L. M. Hallett, P. R. Ehrlich, and H. A. Mooney. (2011). Intervention Ecology: Applying Ecological Science in the Twenty-first Century. BioScience 61:442-450.

[3] Levin, S. A. (1998). Ecosystems and the biosphere as complex adaptive systems. Ecosystems 1:431-436.

[4] World Health Organization. (2016). Urban green spaces and health. Copenhagen: WHO Regional Office for Europe.

[5] Handa, K. L., Freeman, C., Seddona, P. J., A, van Heezika, Y. (2016) A novel method for fine-scale biodiversity assessment and prediction across diverse urban landscapes reveals social deprivation-related inequalities in private, not public spaces. Landscape and Urban Planning 15:33-44.

[6] Gunderson, L. (2000). Ecological resilience - in theory and application. Annual Review of Ecological Systems, 31, 425439.

[7] Schaefer, V. H. (2009). Alien invasions, ecological restoration in cities and the loss of ecological memory. Restoration Ecology, 17, 171-176.

[8] Sun, Z., Ren, H., Schaefer, V., Lu, H., Wang, J., Li, L. and N. Liu. (2014). Quantifying the ecological memory during forest succession: a case study from lower subtropical forest ecosystems in South China. Environmental Monitoring and Assessment. Ecological Indicators DOI 10.1007/s10661-0144000-6

[9] Schaefer, V. H. (1999). The Green Links Project: A Holistic Approach to Habitat Restoration in Cities. Ecological Restoration. Ecological Restoration, 17, 250-251.

[10] Hobbs, R. J., L. M. Hallett, P. R. Ehrlich, and H. A. Mooney. (2011). Intervention Ecology: Applying Ecological Science in the Twenty-first Century. BioScience, 61, 442-450.

[11] Levin, S. A. (1998). Ecosystems and the biosphere as complex adaptive systems. Ecosystems, 1, 431-436.

[12] Blair R B. (1996). Land use and avian species diversity along an urban gradient. Ecological Applications, 6, 506-519.
[13] Rubin, E. S., W. M. Boyce, C. J. Stermer, and S. G. Torres. (2002). Bighorn sheep habitat use and selection near an urban environment. Biological Conservation, 104, 251-263.

[14] Morneau, F., R. Decarie, R. Pelletier, D. Lambert, J. L. DesGranges, and J. P. Savard. (1999). Changes in breeding bird richness and abundance in Montreal parks over a period of 15 years. Landscape and Urban Planning, 44, 111-21.

[15] Environment Canada. (2005). How Much Habitat is Enough? ( $2^{\text {nd }}$ ed.) Canadian Wildlife Service. Downsview, Ontario.

[16] Environmental Law Institute. (2003). Conservation Thresholds for Land Use Planners Washington D. C.

[17] Forman R. T. T. and L. E. Alexander. (1998). Roads and their major ecological effects. Annual Review of Ecology, Evolution and Systematics, 29, 207-231.

[18] Galli, A. E., C. Leck, and, R. Forman. (1976). Avian distribution patterns in forest islands of different sizes in central New Jersey. Auk, 93, 356-64.

[19] Mann, C. C. (2005). 1491: New Revelations of the Americas before Columbus. New York, NY: Knopf Doubleday Publishing Group.

[20] Seastedt, Timothy R., Richard J. Hobbs, and Katharine N. Suding. (2008). "Management of Novel Ecosystems: Are Novel Approaches Required?" Frontiers in Ecology and the Environment, 6, 547-53.

[21] Schaefer, V. and A. Tillmanns. (2014). Listening to Ecosystems: Ecological restoration and the uniqueness of place. Ecological Restoration, 33, 3-9.

[22] Hourdequin, M., and Havlick, D, G. eds. (2016). Restoring Layered landscapess, History, Ecology and Culture. New York: Oxford University Press.

[23] Edgar, T. (2007). Restoration in mind: placing ecological restoration in a cultural context. Environments, 35, 25-43.

[24] University of Victoria. (2015). University of Victoria Campus Plan. Office of Campus Planning and Sustainability.

[25] Kathrens, L., Jennings, J. and V. Schaefer. (2016). University of Victoria Invasive Species Management Strategy. Office of Campus Planning and Sustainability. University of Victoria. $171 \mathrm{pp}$.

[26] Gye J. (2003). Discussion Paper: Towards and Urban Forest Stewardship Strategy for Southern Vancouver Island. Victoria, BC: Habitat Acquisition Trust.

[27] Sandborn, C. (1996). Green Space and Growth: Conserving Natural Areas in BC Communities. Commission on Resources and the Environment, Fisheries and Oceans Canada, Ottawa.

[28] Higgs, E. (2003). Nature by Design - People, Natural Process, and Ecological Restoration. MIT Press, Cambridge, MA.

[29] Yaksic, V. and F. Nelson. (2016). "Crime Prevention Through Environmental Design" Master of City and Regional Planning Terminal Projects. 70. http://tigerprints.clemson.edu/mcrp/70 